\title{
THE POSSIBLE INFLUENCE OF RISK MANAGEMENT, FORECASTING, AND PERSONNEL TRAINING IN PHYSICAL ASSET MANAGEMENT
}

\author{
J.S. Schoeman ${ }^{1} \&$ P.J . Vlok ${ }^{2 *}$ \\ Department of Industrial Engineering \\ Stellenbosch University, South Africa \\ 2pjvlok@sun.ac.za
}

\begin{abstract}
ABST RACT
The work presented in this paper highlights the possible effects of risk management, forecasting, and personnel training in the physical asset management environment. Each section is taken separately, and an argument is formed as to why it is important and what portion of the physical asset management five-year budget each should receive. This paper considers the long-term and short-term benefits in its conclusion that risk management should receive 60 per cent of the budget, personnel training 25 per cent, and forecasting the final 15 per cent.
\end{abstract}

\section{OPSOMMING}

Hierdie studie beklemtoon die moontlike effekte wat risiko bestuur, voorspelling van voorvalle, en die opleiding van personeel kan hê binne die fisiese bate bestuur omgewing. Die afdelings word elk apart bespreek, en 'n argument word gevorm om te sê waarom die afdeling belangrik is en watter bedrag van ' $n$ maatskappy se vyf- jaar begroting elk moet ontvang. Die finale besluit was dat risiko 'n totaal van 60 persent van die begroting moet ontvang omdat dit so ' $n$ breë afdeling is, die opleiding van personeel vereis 25 persent, en die voorspelling van gebeure die laaste 15 persent.

\footnotetext{
${ }^{1}$ The author was enrolled for a MEng in the Department of Industrial Engineering, Stellenbosch University

* Corresponding author
} 


\section{$1 \quad$ INTRODUCTION}

Most, if not all, companies with physical assets that they use to create value have a limited budget to manage these assets. This paper takes a closer look at the physical asset management (PAM) environment, and advises the reader on how to divide the organisation's PAM budget into three critical areas.

Asset management (AM) is essential to ensuring equipment availability, quality products, on-time deliveries, and plant safety [1]. AM is much more than just the maintenance of equipment; as mentioned in Hastings [17], it encompasses the following:

- identifying what assets are needed,

- identifying funding requirements,

- acquiring assets,

- $\quad$ providing logistic and maintenance support systems for assets, and

- $\quad$ disposing of or renewing assets.

This must all be done while still ensuring that the desired objectives are met and that the strategies used are in line with the business objectives [17]. In more mature organisations, PAM has proven itself to be an investment and not just an expense [8].

There has been a great demand for PAM within organisations; and this realisation led to the creation of the Publicly Available Specification 55 (PAS 55) document. PAS 55 was created and published in 2004 by the British Standards Institute to provide a framework to manage mainly physical assets, although it can be applied to all asset types. The scope of those considered to be physical assets by PAS 55 [20] are shown in Figure 1: this gives the reader an idea of all the different areas to which PAS 55 can be applied. The document was created with asset-intensive organisations in mind. This framework is a continuous process, and the different processes can be grouped and described in the Deming Cycle structure (plan, do, check, and act): this helps to structure the AM system [20]. AM is an on-going process, and manages the assets over their entire life cycle - something that many organisations do not understand.

The PAS 55 document proved so successful that an ISO standard (ISO 55000) was created and is currently in the final stages of being published. This will be an international standard for PAM, largely based on the PAS 55 document [2]. Both documents are all about reducing and managing risk associated with the physical assets in an organisation. Thus risk management is a vital area within the PAM environment - although the entire PAM process can also be seen as risk management. In order to achieve AM excellence, risk management is one strategy used to identify and execute AM activities. Risk management alone has many supporting tools (activities executed to enforce risk management) that can be applied, but that are sometimes so specific that special expertise and their own budgets are needed.

One of these tools is the forecasting of events: it plays a large role in the modern PAM environment [3]. The residual life of equipment is calculated to try to prevent costly failures from occurring. This makes use of condition monitoring (CM) to capture the data needed to make the predictions [9]. Historical data then becomes the foundation of the future predictions, and so plays an important role. Even in the modern age it still happens that small organisations cannot afford the CM equipment, or the measuring equipment does not fit on to the equipment that needs to be measured. This then causes a lack of historical data, preventing the engineers from making predictions. Determining when a piece of equipment will break is a very important part of PAM, and can save organisations a lot of money. 


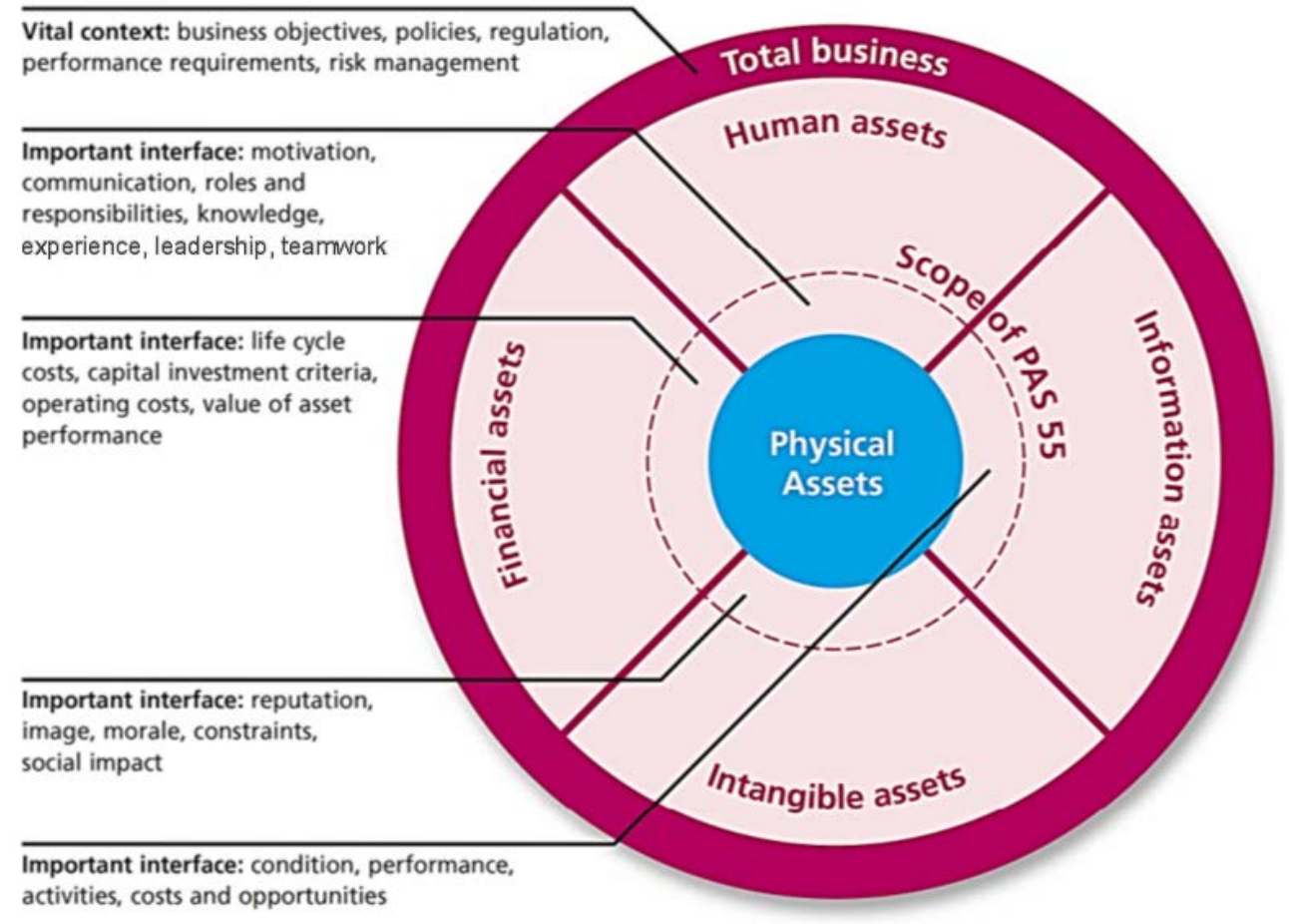

Figure 1: Scope of PAS 55 [20]

The support infrastructure of the AM system is a large part of the system, and so it cannot be ignored. The correct training for personnel is essential to get the maximum efficiency from the PAM strategy. People and their leadership are just as important as the AM system itself, and training of personnel is a key factor to ensure that the required knowledge and skills are present [17].

The next section discusses risk management, its importance, and where it fits into PAS 55. The same is then done in Sections 3 and 4 to stress the importance of the different fields and to justify why they should receive a portion of an organisation's PAM budget. Section 5 presents the main reasons why it is a good idea that these specific areas should be funded by the PAM budget of an organisation. The last section then wraps up the discussions and presents what portions of the budget should be assigned to each area.

\section{RISK MANAGEMENT}

The decisions that are made on a day-to-day basis are based on the interpretation of the data that is currently available to the one deciding. It is known that data is full of uncertainty because of human error, biased readings, equipment error, etc. Unfortunately uncertainty is part of our everyday lives. Risk is defined in ISO 31000 as "the effect of uncertainty on objectives", whether these effects are positive or negative. The idea of risk management is not to eliminate risk, since this is impossible, but rather to decide which risks are worth taking and which ones we want to avoid completely [5,14]. Risk management as described in Hubbard [4] is the identification, assessment, and prioritisation of risks, followed by coordinated and economical application of resources to minimise, monitor, and control the probability and/or impact of unfortunate events. Risk can be seen as the product of the probability of an event occurring and the consequences of that event. Hastings [17] states that ranking the potential events can then help to identify, 
assess, and prioritise the risks involved. Risk management is a very broad field, and it should be carefully monitored and managed.

The risks faced in PAM include environmental or health and safety risks; intangible losses such as damage to the brand name or to the organisation's reputation can also be a result of some of the risks [17]. It is important to manage the risks in PAM. It is a moral obligation to try to protect the people we work with, the environment we live in, and the future of the organisation. As with financial investments, different risks are considered when we want to do a long-term or a short-term assessment [5]. Complying with the PAS 55 document also requires risk management: the document explicitly states in just over 71 per cent of its sections that some form of risk management should be done.

When managing physical assets, the keyword is reliability: equipment with a higher reliability means lower risk $[6,7]$. The reliability of equipment has been proven to relate directly to the safety of workers, environmental incidents, and cost effectiveness [7]. The relationship differs between industry types, but it is assumed that the effects only differ in magnitude and that there is never an inverse effect [6]. The correct maintenance strategies will increase the reliability of equipment in a plant; and with increased reliability comes a higher use of assets. Moore's study [7] showed that fewer environmental incidents occurred as the number of assets used increased, and the number of injuries decreased as the number of preventative and predictive work orders increased. The same study also revealed that the injury rate decreased as the maintenance schedule compliance increased [7]. This study indicates that risk can be reduced by applying AM activities in the appropriate areas. There is no doubt that correctly managing risks will have a beneficial impact on the AM system of an organisation. Part of the risk management is selecting the correct AM activities and applying them. Forecasting of events and personnel training are also discussed in the context of risk management, but because they can have such a large impact in the PAM environment, and because they require so much attention, they are discussed separately.

A different study - carried out by the Aberdeen Group in the manufacturing industry categorised organisations into three different groups: the best-in-class, the industry average, and the laggards. Shah and Littlefield [14] used two key performance indicators (KPIs) to separate the organisations: 'percentage unscheduled asset down time' and 'percentage production compliance'. The top 20 per cent of organisations are considered to be the 'best-in-class', while the bottom 30 per cent are the 'laggards' and the remaining 50 per cent are the 'industry average'. On average the best-in-class had 11 per cent lower asset down time and 14 per cent more products and processes in compliance [14]. They achieved their best-in-class results by applying risk management strategies, such as creating or improving visibility into the top risks, providing real-time visibility into operations, and educating employees on how to manage operational risks [14]. With this study, the relative value of risk management is seen and found to be rather substantial. The strategies applied by the best-in-class organisations are another indication that the training of personnel should be looked at separately because it is capable of having a large financial benefit to the organisation.

Considering the evidence of the effects of a mature risk management system, it is worthwhile investing money into this field over a period of time. Many organisations see a five-year budget as short-term; this will most likely be the minimum consideration time when wanting to develop a more mature and therefore more effective and efficient risk management system. Having the PAM system of an organisation act as a financial benefit requires commitment and hard work, as explained in Fogel [8].

\section{FORECASTING}

Forecasting of events is a useful tool because it can be used to reduce unexpected asset down time, reduce the risk of costly and/ or dangerous failures, and prevent redundant maintenance activities [9]. The condition of certain machines and their components affects 
the quality of the products produced; therefore it is important to know the condition of the machines at any particular time. Forecasting of events is a tool used to support the risk management process, because it can help to determine the possible time of an unwanted event, allowing predictive maintenance to be done. Forecasting also helps to avoid unnecessary preventative maintenance actions, saving money that would otherwise be spent on replacing healthy equipment. Considering this, it can be seen that if implemented correctly, the forecasting of unwanted events can have a favourable impact on an organisation's balance sheet and reputation. Forecasting requires the aid of CM, which measures the current health of the equipment and provides analysts and engineers with the data needed to make predictions [9].

Earlier methods of maintenance, which were 'usage-based' (also known as preventative maintenance) and 'run-to-failure', did not consider the immediate condition of the equipment. Condition-based maintenance, also known as 'predictive maintenance', takes into consideration the current health of the equipment and uses the CM data to make predictions as to how much longer the equipment is likely to survive [10]. This remaining life of the equipment is known as the 'residual life', and different mathematical models have been developed to predict the residual life of certain equipment with considerable accuracy [10]. By knowing more or less when a piece of equipment is going to fail, the risk to the operators and to the production schedule can be calculated and analysed, helping to decide which actions should be taken. Here both functional breakdowns and physical breakdowns are considered to be failures.

Forecasting goes hand-in-hand with $\mathrm{CM}$ and data analysis, since it needs both fields. Expert opinion also plays a role in forecasting events: the best forecasting methods combine quantitative analysis with the opinion of experts in a certain field to make the prediction [11]. If you are able to predict, for example, when the gearbox of just one haul truck running in a mine is going to break, it could save the mine the unplanned asset down time and also save the possible risk of an accident caused by the failure of the gearbox somewhere on-site. The relative value of the forecasting of events can differ greatly, depending on the equipment to which they are applied. Correct predictions can save an organisation the cost of something as small as a single bearing, up to something as big as the turbines used by ESKOM to generate South Africa's electricity.

Since forecasting requires data from CM and impacts on the maintenance method used, it overlaps different sections in the PAS 55 document [20]. Forecasting affects Section 4.3. of PAS 55 [20] because it forms part of the AM strategy used, and it will affect the plans to maintain the equipment. Forecasting also falls within Section 4.4 because it acts as enabler and control measure for monitoring and controlling the equipment. Section 4.5 is about the implementation of plans, and the forecasting of events is an on-going process that should be conducted once all the measurements have been taken by the CM equipment [20]. Forecasting is also relevant in Section 4.6 in PAS 55 [20], because without the CM equipment, no predictions could be done: forecasting therefore plays a role in complying with PAS 55. The forecasting field is still relatively immature, on average, when looking at industry; the majority of organisations are only now starting to invest in the CM equipment, as this technology for making predictions is becoming increasingly cheaper [12].

\section{PERSONNEL TRAINING}

All personnel, from the operator to the technician responsible for the $\mathrm{CM}$ of equipment and the technician responsible for maintenance, must have the proper training and skills to perform their tasks. They should also have the ability to know when a piece of equipment, on which they are not expert, is malfunctioning. This is difficult to enforce because most people today only focus on carrying out their specific task. They do not worry about anything that is not specifically stated on their job card, since they cannot be held accountable for anything beyond that. To comply with the specifications of PAS 55 [20], the organisation that wants the AM tasks done must ensure that the employees responsible for the AM activities have the appropriate education, training, and experience for the job. This 
must also be done if the AM activities are outsourced, as stated in Section 4.4.3 of PAS 55 [20].

Mobley [13] argues that, in order to achieve AM excellence, a culture change must take place at the corporate level. Most of the people at that level still have the perception of predictive technology as only being a tool to prevent failures and to help with maintenance [13]: this must change. If this change takes place, the training of personnel responsible for the equipment's reliability will become a high priority [13]. In order to foster this new culture among lower-level employees, all of the employees that work with the physical assets must be trained and educated about the possible results of the different failures, and be made aware of different situations. Telling all employees that they are accountable gives them a sense of responsibility, and makes them feel that they have more of a purpose than just doing their own bit each day. The training of the employees must be recorded to enable the organisation to prove their compliance with the PAS 55 document [20]. The impact of training is not only to comply with PAS 55 , but also to produce a more effective workforce that is better prepared to react in situations they have never faced before.

Two strategies are used to improve the maintenance methods of organisations: reliabilitycentred maintenance (RCM) and total productive maintenance (TPM). Mobley [13] states that TPM is based on five pillars, and stresses that the most important of these pillars is the education and training of personnel. Training is also one of the key requirements in RCM in order to be successful [16]. When carrying out tasks such as a criticality analysis, RCM expects that the person is well-informed about the task and is able to execute such a process. Operators not only have to know how to operate the equipment in the correct manner, but they should also be able to do routine inspections. The supervisors must also be able to provide proper supervision while knowing what is going on under their noses [13]. It is difficult to assign a quantitative value to the knowledge and skills of employees because it is not possible to know exactly how much their knowledge and skills are worth to the organisation. It is well-known, however, that the effect of expert knowledge and skills in organisations is beneficial.

To comply with the PAS 55 standard, the training of personnel in many different areas is mandatory. The employees responsible for the predictive maintenance must be able to carry out proper predictions, but training is required to ensure that these employees know how to use the required methods. Training is therefore an important supporting pillar of $\mathrm{AM}$; and since risk management is such a broad area, training is required in many risk management fields. As stated in Campbell et al. [16], the training of the necessary personnel must be supported by management. Many organisations have realised this, which has meant that this field is now relatively mature and well-developed. Organisations offer their employees the opportunity to do more training and develop new skills, to benefit not only themselves but the organisation as well.

\section{DISCUSSION}

In an asset-intensive organisation - for example, a mining company - Shah and Littlefield [14] found that an 11 per cent decrease in asset down time [14] could mean a saving of millions of dollars each month. For manufacturing companies, a 14 per cent increase in their products' compliance could save a lot of money, depending on the size of the company. These are just two examples of what can happen when risk is managed correctly. In the PAM environment, managing risk means maintaining equipment correctly, which can increase their reliability, and acquiring the correct assets. The higher reliability of the equipment used can have a positive effect on the risks involved. Therefore it is crucial to have the correct maintenance strategy and implement the tactics correctly. To be able to comply with the PAS 55 [20] framework, risk management must be applied from the start: when setting up the PAM strategy, risk identification and assessment must be done. PAS 55 [20] also requires that a methodology is laid out beforehand for how risks will be managed. As mentioned earlier, risk management is directly related to more than 71 per cent of the sections in the PAS 55 framework. So it is an important field within AM, and cannot be 
ignored. Since training and forecasting are tools that support risk management, it would make sense that the bulk of the budget is allocated to risk management; even if more money is needed in one of the two other areas, it can be awarded to that field through the risk management budget.

The driving factors that caused AM to develop further over the last 40 years were, for the most part, plant/ equipment availability, lower maintenance costs, equipment reliability, minimising environmental effects, and human safety [15]. Forecasting of unwanted events is the basis of predictive maintenance. By applying this maintenance method, a positive effect on all of the driving factors can be achieved [16]. Preventing casualties and/or environmental incidents from occurring at any organisation can save them money and boost their reputation [20]. Environmental incidents can have a quick and drastic effect on the balance sheet of an organisation, as exemplified in the BP oil spill in the Gulf of Mexico. A good reputation increases share prices and improves the marketability to the public, and is more valuable than often realised [20]. More reliable equipment lowers the risk associated with both human casualties and environmental damage. The prediction of equipment's residual life means that money can be saved on maintenance actions and spare parts, since replacements will only be made when needed. A higher reliability and better prediction of failures can yield a higher availability of assets; this enables planned shut-downs, allowing provision to be made for times when the assets are not operating. Forecasting of events is relevant for several areas described in PAS 55 [20]; and it is an important tool that can help an organisation to comply with the PAS 55 document and assist the risk management process.

In order to be able to do a risk analysis, create a maintenance strategy, make predictions, and even to operate the necessary equipment, special knowledge and skills are required. To support the AM framework, the training of employees is essential. Proper training will decrease the number of times that certain jobs have to be repeated, or decrease the number of recurrent and/or specific breakdowns [16]. According to Campbell et al. [16], achieving maintenance excellence requires the combination of four main elements: leadership and people, methods and processes, materials and physical plant, and the systems and technologies used. Training the personnel and ensuring that they have the necessary skills and knowledge falls under the element of leadership and people. According to Hastings [17], training plays an important role in change management, and change is equal to 'uncertainty', which also means 'risk' [18]. Training therefore also helps to manage the risks involved by equipping employees with the tools to make better-informed decisions. Dhillon [19] argues that personnel with inadequate training are also more prone to being injured or to injuring others: by providing proper training to personnel, the risk of injury is reduced and the effectiveness of the work force is increased.

\section{CONCLUSION}

This conclusion is based on the authors' interpretation, and is therefore subjective. The specific choices in this paper are not provided in the literature; but the literature did provide the foundation for the decisions discussed below.

The training of personnel and the forecasting of unwanted events can both be seen as tools to manage the risks involved with PAM. Risk management includes many other actions that may require changes at the managerial level. Therefore risk management should receive the largest portion of the organisation's budget. Since risk management includes those actions mentioned in Section 1, something like acquiring a new physical asset can easily drain the organisation's finances if not properly planned. Since risk management is directly related to nearly 75 per cent of all the sections in the PAS 55 [20] document, it seems fair to dedicate 60 cents of each South African Rand in the PAM budget to risk management. Doing this over a course of five years - and ensuring that the risk management is being implemented correctly - will ensure a mature and effective AM system in the long run. 
The second largest portion of the budget should go towards the training of personnel, because the proper training of employees has a directly positive impact on the risks involved with physical assets. With the correct training, the health risk, environmental risk, and production risk of an organisation can be lowered: and avoiding these risks can have a substantially positive impact on the organisation's balance sheet. It is ideal to train all the people involved in the PAM system, but this is not always possible. Even if only the operators received training to make them more aware of equipment health, this would benefit the organisation. Training can consume precious time; and although this makes it pricey, the returns on it make it worthwhile. PAS 55 [20] states that continual improvement of an organisation's AM system is necessary. Since the improvement of an AM system is seldom cheap, 25 per cent of the budget should be made available for the training of various employees: this will cause the organisation to benefit from their knowledge gained, immediately and in the future. Training supports risk management and forecasting because both of those areas require special training to allow the employees to conduct the activities. It is important to note, however, that these are not the only areas that would benefit from training.

Forecasting is important; but because the decision whether or not to use CM will fall within the risk management section, the money to pay for the equipment will have to come from the risk management budget. The forecasting section will be for the analysis of the collected data and the study of new failure methods or signals. Software packages are available, but as more and more equipment is being fitted with CM equipment, new failure signals are being discovered. There is thus a lot of opportunity for further research. The remaining 15 per cent of the budget should therefore go towards the forecasting section for analysis of the data and further development in the field. If continual improvement occurs over the five years of the budget period, great positive financial implications will be realised. By preventing just one unexpected failure of a critical piece of equipment, an organisation can save the money it invested in forecasting, especially if the failure could have caused a fatality or an environmental risk.

\section{REFERENCES}

[1] Niu, G., Yang, B.-S. and Pecht, M. 2010. Development of an optimized condition-based maintenance system by data fusion and reliability-centered maintenance. Reliability Engineering $\&$ System Safety, 95, pp. 786-796.

[2] Van den Honert, A., Schoeman, J.S. and Vlok, P.J. 2013. Correlating the content and context of PAS 55 to the ISO 55000 series. South African J ournal of Industrial Engineering, 24(2), pp. 2432.

[3] Shull, S.A., Gralla, E., de Weck, O. and Shishko, R. 2006. The future of asset management for human space exploration: Supply classification and an integrated database. Pasadena, CA: J et Propulsion Laboratory, National Aeronautics and Space Administration.

[4] Hubbard, D.W. 2009. The failure of risk management: Why it's broken and how to fix it. John Wiley and Sons.

[5] Connor, G. and Korajczyk, R.A. 2003. "Risk management in asset management", in Modern risk management: A history. Field P, editor. London: Risk Publications, 2003, p. 369.

[6] Sawhney, R. 2012 April. Relationship between worker safety and equipment reliability. [Online]. Available: http:// www. apmadvisor. com/article. asp?is=62\&ord=2\#.U_7z8WOPRm4 [May 2013].

[7] Moore, R. 2011. A reliable plant is a safe plant is a cost-effective plant. IMPACT newsletter, Life Cycle Engineering, vol1. July edition.

[8] Fogel, G. 2013. Is asset management an investment?, Physical Asset Management Course presented at Stellenbosch University Faculty of Industrial Engineering, J ul. 2013.

[9] Wang, W. 2011. Overview of a semi-stochastic filtering approach for residual life estimation with applications in condition based maintenance. Proceedings of the Institution of Mechanical Engineers, Part O: J ournal of Risk and Reliability. 225, pp. 185-197.

[10] Jiang, R. 2011. System availability maximization and residual life prediction under partial observations. PhD thesis, University of Toronto.

[11] Archer, B.H. 1980. Forecasting demand: quantitative and intuitive techniques. International J ournal of Tourism Management, 1, 1980, pp. 5-12.

[12] Stoneman, P. and Diederen, P. 1994. Technology diffusion and public policy. The Economic J ournal, 104, pp. 918-930. 
[13] Mobley, R.K. 2002. An introduction to predictive maintenance. $2^{\text {nd }}$ edition, Elsevier-Science.

[14] Shah, M. and Littlefield, M. 2009. Managing risks in asset intensive operations. Aberdeen Group.

[15] Moubray, J.M. 1997. Reliability-centered maintenance. $2^{\text {nd }}$ edition, Oxford, England: Butterworth Heinemann.

[16] Campbell, J.D., Jardine, A.K.S. and McGlynn, J. 2011. Asset management excellence: Optimizing equipment life-cycle decisions. CRC Press.

[17] Hastings, N.A.J . 2010. Physical asset management. Springer-Verlag London Ltd.

[18] PRAGMA. 2013. Managing Equipment Reliability, Physical Asset Management Course presented at Stellenbosch University Faculty of Industrial Engineering, J ul. 2013.

[19] Dhillon, B.S. 2008. Engineering maintenance: A modern approach. CRC Press.

[20] The British Standards Institution. 2008. Asset management, Part 1: Specification for the optimized management of physical assets, PAS 55-1. 